\title{
TRADUCCIÓN Y MÉTRICA COMPARADA: A PROPÓSITO DE DOS SONETOS DE FRANCISCO DE QUEVEDO
}

\author{
ESTEBAN TORRE
}

Resumen: La comparación de un texto traducido con el texto original, en el proceso de la traducción poética, es la forma más sencilla y evidente del comparativismo literario. Se analizan aquí dos sonetos de Francisco de Quevedo, que son traducciones de poemas de Luís de Camões y Joachim du Bellay. En el caso de este último autor, existen versiones de distintos poetas -Janus Vitalis, Edmund Spenser, Ezra Pound, entre otros- en otras lenguas, que son objeto de estudios comparativos.

Palabras clave: Traducción literaria, métrica, Francisco de Quevedo, Luís de Camões, Joachim du Bellay, Janus Vitalis, Edmund Spenser, Ezra Pound.

Abstract: The comparison of a translated text with the original text, in the process of poetic translation, is the more simple and evident way of literary comparativism. Two sonnets by Francisco de Quevedo are analysed in this paper. Both of them are translations of poems by Luis de Camões and Joachim du Bellay. In the case of the last author, there are versions by several poets - Janus Vitalis, Edmund Spencer, Ezra Pound, among others - into other languages, which are object of comparative studies.

Key words: Literary translation, metrics, Francisco de Quevedo, Luís de Camões, Joachim du Bellay, Janus Vitalis, Edmund Spenser, Ezra Pound. 

$\longrightarrow \mathrm{N}$ el proceso y en el resultado de la traducción no entran realmente en juego distintas lenguas, sino distintos textos, pertenecientes al ámbito de distintas lenguas y culturas. Si el texto traducido tiene carácter literario -poético, rítmico-y se le compara con el texto literario -poético, rítmico- original, ocurre que asistimos al acto más radicalmente puro y elemental del comparativismo literario, en el que aparecen estrechamente unidos los estudios métricos y rítmicos, la literatura comparada, la teoría de la literatura y la teoría de la traducción. Dos famosos sonetos de Francisco de Quevedo -los que comienzan, respectivamente, por los versos «Es hielo abrasador, es fuego helado» y «Buscas en Roma a Roma, oh peregrino»- son paradigma de una auténtica recreación poética en el marco de una patente actividad traductora.

Existen en la historia de la literatura ejemplos notables de reproducciones exactas de un poema en otra lengua. Conocido es el caso de la versión latina llevada a cabo por el poeta veronés Gayo Valerio Catulo (Carm. 51) a partir de un poema griego de Safo de Lesbos (Fr. 31), donde se describen los efectos del amor y los celos: al amante se le ahoga la voz, la visión se le nubla, le zumban los oídos. El original griego ha sido transmitido por el Pseudo-Longino (Sobre los sublime, 10), quien cita precisamente el poema de Safo como ejemplo de la más perfecta selección acumulativa de rasgos descriptivos con vistas a conseguir la elevación del estilo. La versión latina de Catulo constituye, sin duda, un verdadero modelo de traducción poética: lingua sed torpet, tenuis sub artus / flamma demanat, sonitu suopte / tintinant aures, gemina teguntur / lumina nocte (duerme mi lengua, por mi cuerpo corre / un tenue fuego, mis oídos zumban, / se 
extiende el velo de una doble noche / sobre mis ojos). No sólo se reproduce literalmente el contenido de las palabras, sino que se recrea incluso la forma de la oda sáfica, que asimismo se ha procurado conservar en la traducción española. ${ }^{1}$

No faltan otros ejemplos en el dominio de las lenguas modernas, entre ellos los sonetos más arriba citados de Quevedo, en especial el segundo, que, como más adelante tendremos ocasión de ver, forma parte de una más amplia cadena traductológica. Por lo que respecta al primero, el carácter marcadamente esticomítico de su estructura facilita la confrontación del poema de Francisco de Quevedo (1580-1645) con su fuente original, que es un soneto en lengua portuguesa, del que es autor Luís de Camões (c.1524-1580). He aquí ambos textos, el traducido ${ }^{2}$ y el original: ${ }^{3}$

Es yelo abrasador, es fuego helado, es herida que duele y no se siente, es un soñado bien, un mal presente, es un breve descanso muy cansado;

es un descuido que nos da cuidado, un cobarde con nombre de valiente, un andar solitario entre la gente, un amar solamente ser amado;

es una libertad encarcelada, que dura hasta el postrero parasismo; enfermedad que crece si es curada.

Éste es el niño Amor, éste su abismo. ¡Mirad cuál amistad tendrá con nada el que en todo es contrario de sí mismo!

Francisco uevddQ

${ }^{1}$ Vid. TORRE, Esteban: La poesía de Grecia y Roma: Ejemplos y modelos de la cultura literaria moderna, reimp., CSIC y Universidad de Huelva, 2001, págs. $72-73$ y $122-123$.

${ }^{2}$ QUEVEDO, Francisco de: "Soneto amoroso definiendo el amor", Obra poética, I, ed. de José Manuel Blecua, Castalia, Madrid, 1969, pág. 533.

${ }^{3}$ CAMÕES, Luís de: Camões lírico, IV, Sonetos escolhidos, Aillaud e Bertrand, ParísLisboa, s.a. [¿1926?], pág. 39. 
Amor é um fogo que arde sem se ver;

É ferida que dói e não se sente;

É um contentamento descontente;

É dor que desatina sem doer;

É um não querer mais que bem-querer;

É solitário andar por entre a gente;

É nunca contentar-se de contente;

É cuidar que se gagna em se perder;

É um estar-se preso por vontade;

É servir a quem vence o vencedor;

É ter com quem nos mata lealtade.

Mas como causar pode o seu favor

Nos mortais corações conformidade,

Sendo a si tão contrário o mesmo Amor?

Luís amãłes $\mathrm{C}$

La coincidencia textual -copia, calco, imitatio, traducciónsalta a la vista. Dada la estrecha proximidad histórica y genealógica de ambas lenguas, es obvia la identidad de «es herida que duele y no se siente» y «é ferida que dói e não se sente», o «un andar solitario entre la gente» y "é solitário andar por entre a gente». Muy cercanos son también los versos «el que en todo es contrario de sí mismo» y «sendo a si tão contrário o mesmo Amor». Por su parte, la «libertad encarcelada» del primer terceto es una transposición de "um estar-se preso por vontade», es decir, una prisión voluntaria. Se ha invertido el papel sustantivo de la "prisión" («um estar-se preso») del original portugués, que pasa a ser adjetivo («encarcelada») en la versión castellana, mientras que la adjetivación «por vontade» ("voluntaria") se transforma en el sustantivo «libertad». Son dos maneras de ver la misma cosa. Para Camões, el amor es una cárcel que se acepta voluntariamente, mientras que, para Quevedo, es una libertad que se pierde, que se encarcela.

El verso inaugural se complica en la versión de Quevedo. En el original de Camôes, el amor es «um fogo que arde sem se ver», un fuego que arde sin que se vea, una llama invisible. En la versión de Quevedo, encontramos un doble oxímoro: «yelo 
abrasador» y «fuego helado», esto es, "frío / caliente" y "caliente / frío". La sencillez del texto original renacentista ha dado paso al retorcimiento, al doble contraste y a la complejidad de la expresión barroca.

Por lo demás, el poeta español no se atiene estrictamente a la literalidad del texto original, sino que introduce términos de su propia cosecha, sin preocuparse demasiado por la fidelidad de su traducción. Una salva de oxímoros o contrastes paradójicos - «descanso muy cansado», «descuido que nos da cuidado», «enfermedad que crece si es curada»- viene a completar las exigencias del metro y a rellenar los moldes del ritmo y de la rima que le impone el modelo portugués. Se trata, en suma, de un soneto, que proviene de otro soneto muy parecido, tan parecido que podríamos hablar de abierto plagio, si desconociéramos por completo el sentido de la imitatio en la época áurea. En cualquier caso, lo que ocurre es que un gran poema escrito en lengua portuguesa ha dado paso a otro gran poema, esta vez en lengua castellana, aunque el nivel de fidelidad no sea ciertamente muy elevado.

Más interesante y complejo es el segundo de los citados sonetos de Quevedo, que está dedicado a la ciudad de Roma. Inicialmente, se señaló ${ }^{4}$ que la fuente original del mismo era un célebre soneto del poeta renacentista francés Joachim du Bellay (1522-1560). Más tarde, se hizo evidente que la fuente primera ${ }^{5}$ habría de situarse en fechas algo anteriores, concretamente en un inspirado epigrama neolatino del poeta panormitano Janus Vitalis (1485-c.1560). Nuevas versiones se han venido después conociendo, entre ellas las excelentes traducciones inglesas de Edmund Spenser (c.1552-1599) y Ezra Pound (1885-1972), y la

\footnotetext{
${ }^{4}$ Vid. CUERVO, Rufino José: “Dos poesías de Quevedo a Roma”, Revue Hispanique, XVIII, 1908, págs. 432-434.

${ }^{5}$ Vid. LIDA, María Rosa: "Para las fuentes de Quevedo", Revista de Filología Hispánica, I, 1939, págs. 370-371. En realidad, la primacía de Janus Vitalis en relación con el poema ya había sido indicada por Samuel Johnson en el siglo XVIII. En 1980, con motivo del cuarto centenario del nacimiento de Quevedo, el escritor guatemalteco Augusto Monterroso publicó un artículo en el que nos recuerda cómo James Boswell, en su Vida de Samuel Johnson, señala el año 1778 como fecha en la que el Dr. Johson da noticia del hecho. Vid. MONTERROSO, Augusto: "Lo fugitivo permanece y dura", El País, 10 de diciembre de 1980; reproducido en MONTERROSO, Augusto: La palabra mágica, Muchnik, Barcelona, 1985.
} 
polaca de Mikołaj Sęp Szarzyński (c.1550-c.1581). El estudio comparativo de los distintos textos, en lenguas diversas, es verdaderamente aleccionador. Veamos, en primer lugar, el poema ${ }^{6}$ de Quevedo:

Buscas en Roma a Roma, ;oh, peregrino!, y en Roma misma a Roma no la hallas: cadáver son las que ostentó murallas, y tumba de sí propio el Aventino.

Yace donde reinaba el Palatino; y limadas del tiempo, las medallas más se muestran destrozo a las batallas de las edades que blasón latino.

Sólo el Tibre quedó, cuya corriente, si ciudad la regó, ya, sepoltura, la llora con funesto son doliente.

¡Oh, Roma!, en tu grandeza, en tu hermosura, huyó lo que era firme, y solamente lo fugitivo permanece y dura.

Francisco uevdd@

La comparación del texto de Quevedo con la versión francesa de Joachim du Bellay no deja lugar a dudas sobre la deuda contraída por el autor español, aunque es probable que también conociera la primera fuente de Janus Vitalis. Para facilitar la confrontación de los textos, ofrezco traducción española, en prosa. He aquí el soneto ${ }^{7}$ de Joachim du Bellay:

Nouveau venu, qui cherches Rome en Rome

Et rien de Rome en Rome n'aperçois,

Ces vieux palais, ces vieux arcs que tu vois,

Et ces vieux murs, c'est ce que Rome on nomme.

${ }^{6}$ QUEVEDO, Francisco de: “A Roma sepultada en sus ruinas”, Obra poética, I, ed. de José Manuel Blecua, Castalia, Madrid, 1969, pág. 418.

${ }^{7}$ BELLAY, Joachim du: Les Antiquités de Rome, en Les Regrets, précedé de Les Antiquités de Rome et suivi de la Défense et Illustration de la Langue Française, prólogo de Jacques Borel, ed. de S. De Sacy, Gallimard, Paris, 1967, págs. 29-30. 
Vois quel orgueil, quelle ruine: et comme

Celle qui mit le monde sous ses lois,

Pour dompter tout, se dompta quelquefois,

Et devint proie au temps, qui tout consomme.

Rome de Rome est le seul monument,

Et Rome Rome a vaincu seulement.

Le Tibre seul, qui vers la mer s'enfuit,

Reste de Rome. Ô mondaine inconstance!

Ce qui est ferme, est par le temps détruit,

Et ce qui fuit, au temps fait résistance.

\section{Joachim elladu B}

(Recién llegado, que buscas a Roma en Roma y nada de Roma encuentras en Roma: esos viejos palacios, esos viejos arcos que ves y esas viejas murallas es lo que se llama Roma. Mira qué orgullo, qué ruina; y cómo la que sometió al mundo bajo sus leyes, para domeñarlo todo, se domeñó alguna vez a sí misma, y llegó a ser presa del tiempo, que todo lo consume. Roma es el único monumento de Roma, y solamente Roma ha vencido a Roma; sólo el Tíber, que hacia el mar se desliza, queda de Roma. ¡Oh mundanal inconstancia! Lo que está firme se destruye por el tiempo, y lo que huye opone al tiempo resistencia.)

En la traducción del poema de Joachim du Bellay, Quevedo sigue las mismas pautas que en su versión del soneto de Luís de Camões: traduce algunos versos, los más sobresalientes, y reha$\mathrm{ce}^{8}$ el poema conservando las ideas básicas del original. Concretamente, son totalmente superponibles los dos primeros versos y los dos últimos, además de la alusión al río Tíber, que es lo único que todavía nos queda de Roma; precisamente el río, símbolo de lo que pasa y cambia, ya que cuando nos bañamos en un

\footnotetext{
${ }^{8}$ Un detenido análisis semántico del soneto de Quevedo, a partir de un enfoque comparativo, ha sido llevado a cabo por Mijal Gai. Hace ver esta autora cómo existe una firme concordancia entre los procedimientos seguidos por Quevedo y los principios de la poética conceptista expuestos por Baltasar Gracián en su Agudeza $y$ arte de ingenio. Vid. GAI, Mijal: "Buscando en Roma a Roma. Semejanzas y diferencias: Análisis de un soneto de Quevedo", Dispositio: Revista de Estudios Semióticos y Culturales / Americal Journal of Semiotics and Cultural Studies, vol. 10, n. 27, 1985, págs. 97-126; y "El arte de imitar con ingenio: Análisis comparativo de un soneto de Quevedo", Revue Romane, 21, 2, 1986, págs. 208-228.
} 
río nunca nos movemos en las mismas aguas, según el antiguo sentir de Heráclito. En los versos iniciales, se reproduce en parte el poliptoton (en Roma, a Roma) del original francés (Rome, en Rome, de Rome) y de la fuente neolatina (Romam, Roma, Romae), como enseguida veremos. En alusión a las murallas y al estrago del tiempo, la mención de las más conspicuas colinas de Roma-Aventino, Palatino-es en fin de cuentas un oportuno recurso retórico en aras de la rima. Los versos finales - «huyó lo que era firme, y solamente / lo fugitivo permanece y dura»- son análogos en el modelo francés y en las restantes versiones.

Vayamos ahora a la primera fuente, esto es, al epigrama neolatino $^{9}$ del poeta renacentista panormitano Janus Vitalis:

Qui Romam in media quaeris novus advena Roma,

Et Romae in Roma nil reperis media,

Aspice murorum moles, praeruptaque saxa,

Obrutaque horrenti vasta theatra situ:

Haec sunt Roma. Viden velut ipsa cadavera, tantae

Urbis adhuc spirent imperiosa minas.

Vicit ut haec mundum, nixa est se vincere; vicit,

A se non victum ne quid in orbe foret.

Nunc victa in Roma Roma illa invicta sepulta est, Atque eadem victrix victaque Roma fuit.

Albula Romani restat nunc nominis index, Quinetiam rapidis fertur in aequor aquis.

Disce hinc, quid possit fortuna; immota labascunt, Et quae perpetuo sunt agitata manent.

(Tú, nuevo forastero, que buscas a Roma en medio de Roma, y nada de Roma encuentras en medio de Roma, contempla esos grandes lienzos de muralla, esas piedras escarpadas y esos desiertos anfiteatros

${ }^{9}$ Según el texto de Renaissance Latin Poetry, ed. de I.D. McFarlane, Manchester University Press, Nueva York, 1980, págs. 191-192. Cfr. COSTA RAMALHO, A. da: "Um epigrama en latim imitado por vários", Humanitas, 1 (1952), págs. 61-66, y 2-3 (1953-1954), págs. 55-64; GRACIOTTI, S.: "La fortuna de una elegia di Giano Vitale, o le rovine di Roma nella poesia pollaca", Aevum, 34, no . 1-2 (1960), págs. 122-136; SMITH, Malcolm C.:" "Looking for Rome in Rome: Janus Vitalis and his Disciples", Revue de Littérature Comparée, 51, nº 4 (1977), págs. 510-527; SKYME, R.: "Quevedo, du Bellay and Janus Vitalis", Comparative Literature Studies, 19, nº 3 (1982), págs. 281-295; FERRI COLL, José María: "Varia fortuna del epigrama de Janus Vitalis 'De Roma' en la lírica española del Siglo de Oro", Actas del congreso internacional sobre humanismo y renacimiento, vol. II, Universidad de León, León, 1998, págs. 333-339. 
soterrados en un terrible abandono: eso es Roma. Mira cómo hasta los cadáveres de tan gran ciudad aún profieren amenazas altaneramente. Como venció al mundo, también se esfuerza en vencerse a sí misma. Se venció, para que no hubiera en el universo nada que no fuera vencido. Ahora, vencida ya, la invicta Roma está sepultada en Roma, y así es a un tiempo Roma vencida y vencedora. El Albula [el río Tíber] queda sólo ahora como indicio del nombre de Roma, y eso que sus rápidas aguas le llevan a la llanura del mar. Considera así cuánto puede la Fortuna: lo que es firme cede, y lo que continuamente se zarandea permanece.)

Si comparamos el poema francés de Joachim du Bellay con el original neolatino de Janus Vitalis, podemos comprobar que estamos en presencia no ya de una más o menos afortunada imitatio, sino ante una auténtica y lograda traducción. El original de Vitalis consta de catorce versos, dispuestos en forma de siete dísticos elegíacos, es decir, compuestos por un hexámetro y un pentámetro. Du Bellay, siguiendo las pautas métricas que estaban en auge en la época renacentista, traduce tanto los hexámetros como los pentámetros por endecasílabos ("decasílabos", según la convención actual de la métrica francesa). Al tratarse de un poema de catorce versos, opta por la forma canónica del soneto, que es el molde al que se atendrán los traductores subsiguientes, con excepción de Mikołaj Sęp Szarzyński, que utiliza siete dísticos, pero esta vez pareados de rima consonante. ${ }^{10}$

Todo lo que se dice en el epigrama de Vitalis reaparece en la traducción de Du Bellay. Se conserva perfectamente en francés (Rome, en Rome, de Rome) el poliptoton latino (Romam, Roma, Romae) de los versos iniciales, y se expresa en breves palabras (quel orgueil, quelle ruine) el apogeo y la decadencia de la Roma vencedora y vencida (victrix victaque) sólo por la misma Roma (Rome Rome a vaincu seulement). La didascalia final («...immota labascunt, / Et quae perpetuo sunt agitata manent») es fielmente reproducida: «Ce qui est ferme, est par le temps détruit, / Et ce qui fuit, au temps fait résistence».

\footnotetext{
10 "Ty, co Rzym wpośród Rzyma chcqc baczyć, pielgrzymie, / A wżdy baczyć nie możesz w samym Rzyma Rzymie...”, en Mikołaj Sęp Szarzyński: Rytmy abo wiersze polckie, ed. Paulina Buchwald-Pelcowa, Czytelnik, Warszawa, 1978. Vid. BACZYNSKA, Beata: "Dos epitafios a Roma sepultada en sus ruinas: un epigrama polaco de Mikołaj Sęp Szarzyński y un soneto español de Francisco de Quevedo", Scriptura, n. 11, 1996, págs. 31-42
} 
Más exacta y pegada al original es aún la traducción del poeta inglés, contemporáneo de William Shakespeare, Edmund Spenser, ${ }^{11}$ que parte del texto de Joachim du Bellay:

Thou stranger, which for Rome in Rome here seekest, And nought of Rome in Rome perceiv'st at all, These same old walls, old arches, which thou seest, Old Palaces, is that which Rome men call.

Behold what wreak, what ruin, and what wast, And how that she, which with her mighty powre Tam'd all the world, hath tam'd herself at last, The pray of time, which all things doth devowre. Rome now of Rome is th'only funerall, And only Rome of Rome hath victorie; Ne ought save Tyber hastening to his fall Remains of all: O world's inconstancie. That which is firm doth flit and fall away, And that is flitting, doth abide and stay.

\section{Edmund penser $\mathrm{S}$}

(Tú, forastero, que buscas aquí en Roma a Roma, y nada de Roma en Roma percibes en absoluto: esas mismas viejas murallas, viejos arcos, viejos palacios, que tú ves, es lo que se llama Roma. Mira qué destrucción, qué ruina y qué desecho, y cómo la que domeñó a todo el mundo con su tremendo poder, se ha domeñado al fin a sí misma: presa del tiempo, que todo lo devora. Roma es ahora el único monumento funerario de Roma, y sólo Roma ha vencido a Roma. Salvo el Tíber, que camina presuroso hacia su desembocadura, nada queda de todo aquello. ¡Oh inconstancia del mundo! Lo que está firme fluye y se derrumba, y lo que está fluyendo resiste y permanece.)

La traducción de Edmund Spenser es totalmente fiel al texto de Joachim du Bellay. No se añade, no se omite, no se altera nada o casi nada. Los dos versos iniciales contienen los mismos términos y los mismos giros en francés y en inglés. Luego aparecen los viejos palacios (vieux palais, old Palaces), los viejos arcos (vieux arcs, old arches), las viejas murallas (vieux murs, old walls), que es lo que se llama Roma (c'est ce que Rome on nome, is that which Rome men call). Únicamente el orgullo

\footnotetext{
${ }^{11}$ SPENSER, Edmund: Poetical Works, ed. by J.C. Smith and E. De Selincourt, Oxford University Press, Oxford, 1991, pág. 509.
} 
y la ruina del original (quel orgueil, quelle ruine) se modifica, suprimiendo el orgullo y amplificando la idea de la ruina, que pasa a ser destrucción, ruina y desecho (wreak, ruin, wast). Por lo demás, se traduce prácticamente frase por frase, palabra por palabra: presa del tiempo (proie au temps, pray of time), Roma es el único monumento de Roma (Rome de Rome est le seul monument, Rome now of Rome is th'only funerall), solamente Roma ha vencido a Roma (Rome Rome a vaincu seulement, only Rome of Rome hath victorie), sólo el Tíber queda de Roma (le Tibre seul reste de Rome, ne ought save Tyber remains of all), mundanal inconstancia (mondaine inconstance, world's inconstancie). La didascalia final es idéntica en ambas lenguas.

En cuanto a las formas métricas, los endecasílabos del original se traducen asimismo como endecasílabos ("decasílabos", según la convención francesa e inglesa) y el soneto, en su conjunto, se traduce como otro soneto. Ahora bien, el original se atiene al modelo petrarquista, esto es, consta de dos cuartetos, de rimas abrazadas e idénticas, y dos tercetos, mientras que la versión inglesa, obviamente, sigue el modelo isabelino o shakespeariano, con tres serventesios, de rimas cruzadas y diversas, y un pareado final. Fácil le hubiera sido a Spenser conservar el exotismo de la lengua original, escribiendo en inglés un soneto petrarquista; pero prefirió con buen criterio ofrecer al lector inglés un soneto en su propia lengua, no sólo en lo que concierne al léxico y a la sintaxis, sino también en lo que atañe a las formas métricas de la época isabelina.

Tanto el poema de Edmund Spenser como el de Mikołaj Sęp Szarzyński fueron redactados con anterioridad al de Francisco de Quevedo. Existe, lógicamente, la posibilidad de que de uno, de otro o de ambos hubiera tenido noticia el poeta español. De lo que no cabe duda es de su estrecha proximidad al poema de Joachim du Bellay, y más problemática es la influencia directa que hubiera podido recibir de Janus Vitalis.

Quien sí bebió directamente en la fuente de Vitalis fue un erudito coetáneo de Quevedo, el licenciado Luis Martín de la Plaza (1577-1625), sacerdote de la Colegiata de Antequera, que es autor de otra versión castellana del poema: 
Peregrino que, en medio della, a tiento buscas a Roma, y de la ya señora del orbe no hallas rastro: mira y llora de sus muros por tierra el fundamento.

Arcos, termas, teatros, cuyo asiento cubre yerba, esto es Roma. ¿Ves ahora cómo, aun muerta, respira vencedora las amenazas de su antiguo aliento?

Triunfó del mundo y, porque no quedara algo en él por vencer, venciose y yace, quedando el Tibre que su gloria hereda.

De la Fortuna en el poder repara: aquella que era firme se deshace, $\mathrm{y}$ aqueste, que se mueve, firme queda. ${ }^{12}$

En la traducción de Martín de la Plaza, se recoge fielmente la visión de una Roma (victrix victaque, según la elegía de Vitalis) que, para que no quedara nada por vencer, venció y se venció a sí misma, siguiendo el imperioso dictado de la Fortuna. ${ }^{13}$ La mención del poder de la Fortuna (disce hinc, quid possit fortuna, en el texto de Vitalis) no se encuentra en Du Bellay, ni en Spenser, ni en Quevedo, aunque sí en Sęp Szarzyński. En el soneto de Martín de la Plaza reaparecen también los teatros (theatra) y las amenazas (minas) de la altiva Roma: esto es Roma (haec sunt Roma). Pero no siempre la estricta fidelidad es indicio de una buena traducción, y desde luego puede muy bien estar desligada de la belleza. Sucede que, efectivamente, nos encontramos ante una composición dura, forzada, contrahecha. Desde un punto de vista rigurosamente estético, poético, literario, la versión de Luis Martín de la Plaza está a una enorme distancia del sugerente original latino de Janus Vitalis, así como de las brillantes recreaciones de Joachim du Bellay, Edmund Spenser o Francisco de Quevedo.

\footnotetext{
${ }^{12}$ MARTÍN DE LA PLAZA, Luis: Poesías completas, ed. de J.M. Morata Pérez, Diputación Provincial de Málaga, Málaga, 1995, pág. 120.

${ }^{13}$ Vid. LARA GARRIDO, José: "Notas sobre la poética de las ruinas en el Barroco", Analecta malacitana, III, 2 (1980), pág. 390.
} 
Otras traducciones e imitaciones se han venido realizando a lo largo del tiempo. ${ }^{14}$ Algunas tienen un valor meramente anecdótico y libresco. Así, el humanista sevillano Gabriel Álvarez de Toledo (1662-1714) escribe un soneto, ${ }^{15}$ titulado A Roma destruida, inspirado en los poemas de Du Bellay y Quevedo:

Caíste, altiva Roma, en fin caíste, tú, que cuando a los cielos te elevaste, ser cabeza del orbe despreciaste, porque ser todo el orbe pretendiste.

Cuanta soberbia fábrica erigiste, con no menor asombro despeñaste, pues del mundo en la esfera te estrechaste, ¡oh Roma!, y sólo en ti caber pudiste.

Fundando en lo caduco eterna gloria, tu cadáver a polvo reducido, padrón será inmortal de tu victoria;

porque siendo tú sola lo que has sido, ni gastar puede el tiempo tu memoria, ni tu ruina caber en el olvido.

Del alto relieve social y cultural alcanzado por el poeta hispalense da fe el hecho de haber sido bibliotecario mayor de Felipe V,

${ }_{14}$ Incluso se ha querido llevar nuevamente el célebre poema a la lengua latina. Ya don Marcelino Menéndez Pelayo (Historia de los heterodoxos españoles, ed. de Enrique Sánchez Reyes, vol. VI, CSIC, Santander, 1948, pág. 212) había dado noticia de una versión latina del soneto A Roma de Francisco de Quevedo por parte del "eximio scholar inglés Samuel Bond". Se trata, en efecto, de una curiosa y excelente restitución a la lengua latina del poema original, a través de la versión española de Quevedo. Véanse los logrados versos del dístico inicial: Advena qui Romam Roma conquiris in ipsa, / inque locis Romam non reperire potes (BOND, Samuel: Poesías latinas, seguidas de sus Cartas a Miguel Antonio Caro, ed. de Manuel Briceño Jáuregui y Jorge Páramo Pomareda, Instituto Caro y Cuervo, Bogotá, 1974, pág. 145). Menos afortunada es la traducción de Miguel Antonio Caro (1843-1909), procedente también de la versión de Quevedo: Roma ubi sit, frustra Romae scitaberis hospes; / non oculis reperis quam teris ipse pede... (CARO, Miguel Antonio: Latinae interpretationes, en Carmina latina et latinae interpretationes, ed. de Alfredo Becerra, Los Ángeles, 1993, pág. 10).

${ }^{15}$ Sus obras poéticas fueron publicadas, treinta años después de su muerte, gracias a la gestión de Diego de Torres Villarroel. Vid. ÁLVAREZ DE TOLEDO, Gabriel: Obras pósthumas poéticas, con la Burrumaquia, Imprenta del Convento de la Merced, Madrid, 1744. 
además de pertenecer a la Orden de Santiago y ser uno de los fundadores de la Real Academia Española. Sin embargo, escaso o nulo es el valor poético de la composición, que no es más que un subproducto del engolamiento dieciochesco, además de hacer gala de un ritmo reiterativo y malsonante y de una rima increíblemente pobre y desangelada. Esta visión de la invicta y vencedora Roma, como paradigma de la gloria frente a la decadencia, ha merecido en todo caso los aplausos del hispanista estadounidense Russell P. Sebold, quien considera bellos y vigorosos los versos de este soneto, que podría competir con éxito con antecesores tan eximios como Joachim du Bellay y Francisco de Quevedo. ${ }^{16}$ El ilustre hispanista no hace, por otra parte, ninguna referencia a la fuente original de Janus Vitalis, ni a sus más próximos traductores Mikołaj Sęp Szarzyński y Edmund Spenser.

El objetivo principal de estas páginas es hacer evidente cómo la traducción poética - y, concretamente, la traducción del versoes posible, si bien existen grados en la fidelidad y en la calidad del resultado obtenido. Pues bien, entre todas las versiones del poema que nos ocupa, la traducción en lengua inglesa de Ezra Pound, que se declara abiertamente deudora del soneto francés -From the French of Joachim du Bellay-, es un verdadero alarde de exactitud, fidelidad y belleza:

O thou, new comer, who seekst Rome in Rome

And find'st in Rome no thing thou canst call Roman:

Arches worn old and palaces made common

Rome's name alone within these walls keeps home.

Behold how pride and ruin can befall

One who hath set the whole world 'neath her laws,

All-conquering, now conquered, because

She is Time's prey and Time consumeth all.

Rome that art Rome's one sole last monument,

Rome that alone hast conquered Rome the town,

Tiber alone, transient and seaward bent,

Remains of Rome. O world, thou unconstant mime!

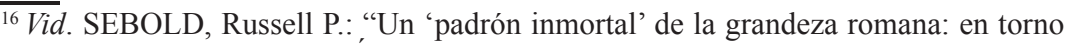
a un soneto de Gabriel Álvarez de Toledo", Studia Hispanica in honorem de R. Lapesa, tomo I, Gredos, Madrid, 1972, págs. 525-530. 
That which stands firm in thee Time batters down, And that which fleeteth doth outrun swift time. ${ }^{17}$

\section{Ezra ound $\mathrm{P}$}

(Oh tú, recién llegado, que buscas a Roma en Roma y no encuentras en Roma nada que puedas llamar romano: viejos arcos erosionados, y palacios convertidos en lugares públicos; sólo el nombre de Roma se cobija en esas murallas. Mira cómo el orgullo y la ruina pueden confluir en quien ha sometido el mundo entero a sus leyes, conquistándolo todo y siendo ahora conquistado, porque es presa del Tiempo, y el Tiempo todo lo consume. Roma, que eres el único monumento que nos queda de Roma, Roma que sólo tú has conquistado la ciudad de Roma: sólo el Tíber, que pasa y se inclina hacia el mar, queda de Roma. ¡Oh mundo, tú, inconstante pantomima! Lo que está firme en ti el Tiempo lo derrumba, y lo que fluye escapa al movedizo tiempo.)

Como quiera que el original francés data del siglo XVI, en la versión inglesa se conservan algunos rasgos arcaizantes (consumeth, fleeteth). Por lo demás, se reproduce el texto fielmente, prácticamente palabra por palabra, con metro y ritmo idénticos, y con rima (obviamente distinta del original) consonante y distribuida en cuartetos y tercetos según el modelo petrarquista. Ezra Pound supera, sin duda, a Edmund Spenser. Su texto es más fluido, más rico en sonoridades, más flexible. Y, además, es absolutamente fiel al original de Du Bellay. En la versión de Spenser, el contraste entre el orgullo y la ruina -quel orgueil, quelle ruine- de la ciudad de Roma había desaparecido. No se hacía mención del orgullo, y se magnificaba la ruina -what wreak, what ruin, and what wast-, mientras que en el soneto de Pound -behold how pride and ruin-se respeta escrupulosamente la literalidad del original.

No he querido quedar al margen de este apasionante proceso de recreación textual. He aquí mi propia versión española:

Buscas a Roma en Roma, forastero,

y no encuentras de Roma en Roma nada;

viejos muros, grandeza soterrada

en un foro ruinoso y altanero:

17 POUND, Ezra: Personae: the collected shorter poems of Ezra Pound, New York Direction Book, Nueva York, 1971, pág. 40. 
eso es Roma. La Roma, que primero a todos sometió, también airada se somete a sí misma, y sepultada yace, por sojuzgar al mundo entero.

Casi no existe ya memoria alguna de la Roma vencida y vencedora: sólo nos queda el Tíber, mientras huye

hacia el mar. ¡Cuánto puede la Fortuna! Lo que era firme, el tiempo lo devora, y permanece lo que pasa y fluye.

La expresión «eso es Roma»-haec sunt Roma-, en el segundo cuarteto, y la alusión a la Fortuna - «jcuánto puede la Fortuna!»: quid possit Fortuna-, en el último terceto, revelan la conexión directa del soneto con la fuente primera, esto es, el epigrama neolatino de Janus Vitalis. Tómelo el lector como un ejercicio más de práctica traductológica y, si le place, añádalo a la larga serie de versiones que perpetúan la grandeza del poema original. Como apunté en otro lugar, ${ }^{18}$ tal vez una de las características del poema logrado sea su capacidad de desdoblamiento en otras recreaciones y en otras lenguas.

${ }^{18}$ TORRE, Esteban: "Poesía y traducción poética: los sonetos ingleses de José María Blanco-White”, Archivo Hispalense, XC, 273-275, 2007, págs. 281-295. 